\title{
ACHIEVEMENT OF AWARENESS IN A DIABETIC POPULATION
}

\author{
MIRZA AZIZUL HOQUE ${ }^{1}$, MD. SIRAJUL ISLAM ${ }^{2}$, MD. ABDUL MALEQUE KHAN ${ }^{3}$, REHANA AZIZ ${ }^{4}$, HAM \\ NAZMUL AHASAN 5
}

\begin{abstract}
This cross-sectional survey was carried out during the period, October 2005 to December 2005, among 184 randomly chosen diabetic patients in Khulna Diabetic Centre, Khulna, Bangladesh, to evaluate the knowledge of the patients for their control of diabetes mellitus and also to explore the association(s) of their attitude and knowledge regarding diabetic awareness towards educational status and socio-demographic profile.

In this study, we found a significant difference, in diabetic awareness to keep correct blood glucose level, in different educational group. But, it did not influence the subjects of different educational group to visit the diabetic clinic. There was no significant difference in the knowledge of correct blood glucose level and in regularity of visit to the diabetic clinic, in rural and urban people. Knowledge of correct blood glucose level varied significantly among male and female patients, although, no significant variation was found among them in visiting to the diabetic clinic.
\end{abstract}

We can conclude that, diabetic education programs can improve self-regulatory behavior and in the long run, can reduce morbidity and mortality.

\section{Introduction}

Diabetes mellitus (DM) continues to be a major noncommunicable disease threat to global public health. 1, 2 More than 170 million people worldwide have diabetes, and this figure is projected to be more than double by the year 2030 , if current trends continue. ${ }^{3}$ It will mostly increase in South Asia. In 2007, a United Nations (UN) resolution was adopted to mark diabetes mellitus as a significance global public health issue. ${ }^{4}$ In 2007, the International Diabetes Federation (IDF) estimated that 3.8 million or $4.8 \%$ of people living in Bangladesh have diabetes. By 2025, that number is expected to grow to 7.4 million or $6.1 \%$ of the population. This explosion will place Bangladesh among the top ten countries, in terms of the number of people living with diabetes, by the year 2025 . At that date, $80 \%$ of all diabetes cases will be the burden in the low and middle socioeconomic countries. ${ }^{5}$

Although diabetes mellitus is an incurable disease, it can be managed properly, if the subjects are trained. Proper self-management requires patients to be aware of the nature and consequences of the disease course, its risk factors, dimensions of treatment and its complications. ${ }^{6,7}$

\section{Subjects and Methods}

This cross-sectional survey was conducted from October 2005 to December 2005, among randomly chosen diabetic patients, in Khulna Diabetic Centre, Khulna, Bangladesh. A total 184 diabetic patients were surveyed. Those of greater than 16 years old and who could understand the instructions of the survey were included. All the subjects had answered voluntarily and confidently against the administered pre-tested questionnaires. The questions were aimed to assess the awareness of diabetes mellitus in relation to its control, management, treatment and complications. After collection of data, they were checked and verified and data analysis was performed by using Statistical Package for Social Science (SPSS, version 10). All the surveys were administered in the presence of at least two of the authors.

1. Associate Professor of Endocrinology, Dhaka Medical College, Dhaka

2. Assistant Professor of Medicine, Khulna Medical College, Khulna

3. Assistant Professor of Ophthalmology, Khulna Medical College, Khulna

4. Assistant Professor of Biochemistry, Chittagong Medical College, Chittagong

5. Professor of Medicine, Dhaka Medical College, Dhaka

Correspondence : Dr. Mirza Azizul Hoque, Associate Professor of Endocrinology, Dhaka Medical College, Dhaka 


\section{Results}

A total 184 individuals were surveyed. Mean age of the patients was 45.29 and the SD was \pm 10.89 years. Mean $( \pm \mathrm{SD})$ duration of DM of the patients was 6.99 $( \pm 5.49)$ years. Number of male patients were 57 (31.1\%) and $127(68.9 \%)$ were female. Figure-1 depicts the educational status of the patients.

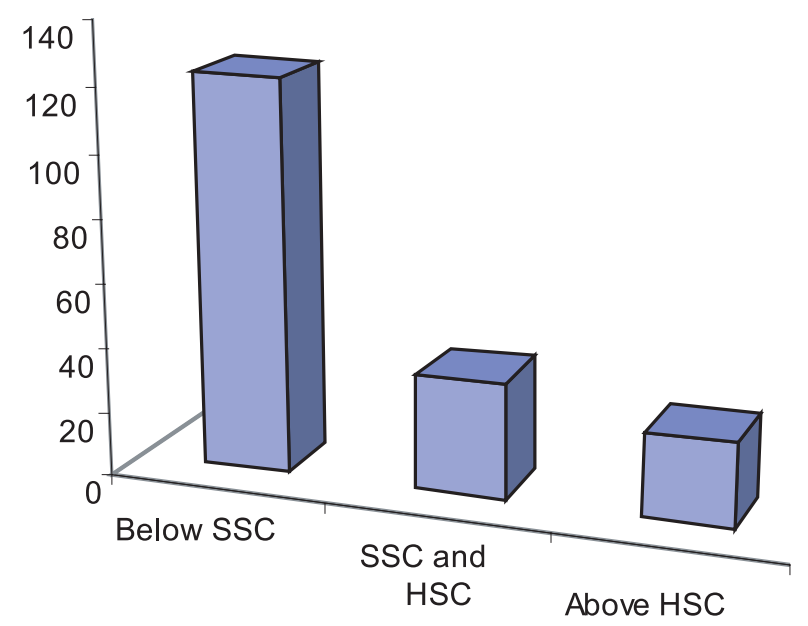

Fig.-1: Distribution of patients according to educational status.
$45.1 \%$ (83) patients had monthly household income of $5000-10,000$ taka, followed by $35.3 \%$ (65) with a monthly household income of below 5000 taka. Lion share of the patients were house wife (62.0\%), followed by service holder (14.7\%).Among the patients 78.3\% (144) were from urban area and only $21.7 \%$ (40) were from rural area. A family history of DM was present in $47.3 \%$ (87) of cases (Fig-2).
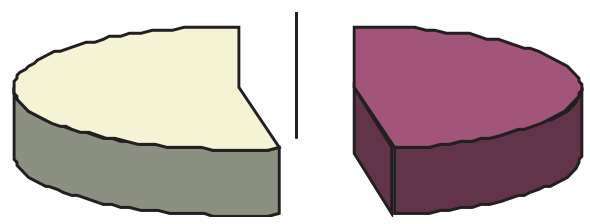

Present $\square$ Absent

Fig.-2: Distribution of patients according to family history of DM.

In this study we found significant difference (ChiSquare $=24.47, \mathrm{p}<0.001)$ in the knowledge of correct blood glucose level for good control of DM in different educational group (Table-1).

Table-I

Association between education and knowledge for good control of blood glucose level in diabetic management.

\begin{tabular}{|c|c|c|c|c|c|}
\hline \multirow[t]{2}{*}{ Level of Education } & \multicolumn{4}{|c|}{ Amount of blood glucose in $\mathrm{mmol} / \mathrm{L}$ good for health } & \multirow[t]{2}{*}{ Total } \\
\hline & $5.0-7.0$ & 7.1-9.0 & $9.1-11.0$ & Not known & \\
\hline$\overline{\text { Below SSC }}$ & $22(18.0 \%)$ & $20(16.4 \%)$ & $1(0.8 \%)$ & $79(64.8)$ & $122(100 \%)$ \\
\hline SSC and HSC & $12(33.3 \%)$ & $09(25.0 \%)$ & $1(2.8 \%)$ & 14(38.9) & $36(100 \%)$ \\
\hline Above HSC & $09(34.6 \%)$ & $12(46.2 \%)$ & $00(0.0 \%)$ & $05(19.2)$ & $26(100 \%)$ \\
\hline Total & $43(23.4 \%)$ & $41(22.3 \%)$ & $02(1.1 \%)$ & $98(53.3)$ & $184(100 \%)$ \\
\hline
\end{tabular}

Visit to the diabetic centre did not differ (Chi-Square $=4.62, \mathrm{p}=0.59)$ among different educational groups of patients (Table-II).

Table-II

Association between education and regularity in visit to the diabetes centre.

\begin{tabular}{lccccc}
\hline Level of & \multicolumn{3}{c}{ Regularity of visit in diabetic centre by study subjects } & Total \\
Education & Last 3 visits regular & Last 2 visits regular Last visit regular & No visit regular & \\
\hline Below SSC & $58(47.5 \%)$ & $25(20.5 \%)$ & $5(4.1 \%)$ & $34(27.9 \%)$ & $122(100 \%)$ \\
SSC and HS C & $21(58.3 \%)$ & $7(19.4 \%)$ & $1(2.8 \%)$ & $7(19.4 \%)$ & $36(100 \%)$ \\
Above & $17(65.4 \%)$ & $5(19.2 \%)$ & $0(0 \%)$ & $4(15.4 \%)$ & $26(100 \%)$ \\
\hline Total & $96(52.2 \%)$ & $37(20.1 \%)$ & $6(3.3)$ & $45(24.5 \%)$ & $184(100 \%)$ \\
\hline
\end{tabular}

There was no significant difference (Chi-Square $=1.48, \mathrm{p}=0.68$ ) in the knowledge of correct blood glucose level between rural and urban patients groups. (Table-III). 
Table-III

Association between residences of the individuals with the blood glucose level beneficial for health.

\begin{tabular}{lccccc}
\hline Residence & \multicolumn{4}{c}{ Amount of blood glucose beneficial (in mmol/L) for good health } & \multirow{2}{*}{ Total } \\
& $5.0-7.0$ & $7.1-9.0$ & $9.1-11.0$ & Not known & \\
\hline Rural & $11(27.5 \%)$ & $7(17.5 \%)$ & $0(0 \%)$ & $22(55 \%)$ & $40(100 \%)$ \\
Urban & $32(22.2 \%)$ & $34(23 . \wedge \%)$ & $2(1.4 \%)$ & $76(52.5 \%)$ & $144(100 \%)$ \\
Total & $43(23.4 \%)$ & $41(22.3 \%)$ & $2(1.1 \%)$ & $98(53.4 \%)$ & $184(100 \%)$ \\
\hline
\end{tabular}

There was also no significant difference (Chi-Square $=4.13, \mathrm{p}=0.247)$ in the regularity in visiting the diabetic clinic between rural and urban groups of patients. Knowledge of correct blood glucose level also varied significantly $($ Chi-Square $=16.61, \mathrm{p}=0.001)$ among male and female patients $($ Table IV).

\section{Table IV}

Association between sex and knowledge of normal blood glucose level.

\begin{tabular}{lccccc}
\hline Sex & \multicolumn{4}{c}{ Amount of blood glucose beneficial (in mmol/L) for good health } & Total \\
& $5.0-7.0$ & $7.1-9.0$ & $9.1-11.0$ & Not known & \\
\hline Male & $17(29.8 \%)$ & $19(33.3 \%)$ & $2(3.5 \%)$ & $19(33.3 \%)$ & $57(100 \%)$ \\
Female & $26(20.5 \%)$ & $22(17.3 \%)$ & $0(0.0 \%)$ & $79(62.2 \%)$ & $127(100 \%)$ \\
Total & $43(23.4 \%)$ & $41(22.3 \%)$ & $2(1.1 \%)$ & $98(53.3 \%)$ & $184(100 \%)$ \\
\hline
\end{tabular}

But there was no significant difference (Chi-Square $=1.29, \mathrm{p}=0.731$ ) in regularity of visit to the diabetic centre between male and female patient groups.

\section{Discussion}

There is virtually, no epidemiological study from Bangladesh assessing the level of knowledge about diabetes in general or diabetic population. Educational status was found to be positively correlated with knowledge of diabetes, in a study conducted at the Aga Khan University Hospital Karachi, Pakistan. ${ }^{8}$ A study carried out in India, among general population showed grossly inadequate knowledge regarding diabetes and suggested urgent massive diabetic education program. ${ }^{9}$ In this study, we found a significant difference in the knowledge of individual regarding correct blood glucose level among different educational groups. On the other hand, regularity of visit to the diabetic centre did not differ among different educational groups of patients. This finding is consistent with other studies ${ }^{10,11}$ albeit with a few exceptions. ${ }^{9}$ One implication of the present findings is that despite limited knowledge of diabetes, individual education might play a critical role to grip the emerging epidemic of diabetes in near future. A study conducted in Singapore on public awareness of diabetes mellitus showed that people were well informed regarding the disease. This study had concluded that health care professionals should be more proactive in disseminating health information about diabetes to the people. ${ }^{12}$

We found no significant difference neither in the knowledge of individual to know the correct blood glucose level nor in the regularity to visit the diabetic centre between rural and urban groups of patients. Of the African rural patient population, $52.2 \%$ had lower awareness of blood glucose compared to $47.5 \%$ of the African urban dwellers. ${ }^{13}$ The research findings among aboriginal diabetic patients in rural South Australia indicated that a lack of knowledge regarding management issues influenced the effects of diabetes on their lifestyle. ${ }^{14}$

In our study, overall male knew more than female about healthy life style. This finding agree with the findings of Nisar et al. conducted in Pakistan. ${ }^{15}$

Another study conducted in rural Northwest of Pakistan regarding knowledge of diabetes among patients, showed that high proportion of males have better understanding of diabetes symptoms, signs and 
complication as compared to females and gender difference was not significant when question about suitable diet was asked for. ${ }^{16}$ This study also showed that males were more aware of diabetes mellitus, healthy diet and life style modification. ${ }^{16}$

\section{Conclusion:}

Diabetes mellitus is a heterogeneous disease associated with long term morbidity, mortality and imposes individual, national or global enormous negative economic impact, if left untreated or maltreated. It is spreading all over the world, progresses nearly a geometric course and causing a major reason for apprehension. The main approach to manage this problem is to educate, convince and create a suitable environment to learn the nature and consequences of the disease, both for the affected and non-affected population of the community. Heath care professionals, different kind media, political workers, teachers of different levels may play a significant role in achieving awareness for effective control and management of this globally affected issue.

\section{References:}

1. Abegunde DO, Mathers CD, Adam T, Ortegon M, Strong K. The burden and costs of chronic diseases in low-income and middle-income countries. Lancet 2007; 370:1929-38.

2. Hjelm K, Mufunda E, Nambozi G, Kemp J. Preparing nurses to face the pandemic of diabetes mellitus: a literature review. J Adv Nurs 2003; 41:424-34.

3. Wild S, Roglic G, Green A, Sicree R, King H. Global prevalence of diabetes: estimates for the year 2000 and projections for 2030. Diabetes Care 2004; 27 :1047-53.

4. Epidemiology of Diabetes Mellitus in Bangladesh. 2008. available at: http://www.med.uio.no/ disputaser/m-o/muhammad-abdur-rahim.xml

5. International Diabetes Federation. Diabetic Association of Bangladesh supports Unite for Diabetes 2006. available at: http://www.world diabetesday.org/node/2918

6. Habib SS, Aslam M. Risk factors, knowledge and health status in diabetic patients. Saudi Med J 2003; 24 :1219-24.
7. Mehrotra R, Bajaj S, Kumar D, Singh KJ. Influence of education and occupation on knowledge about diabetes control. Natl Med J India 2000; 13:6293-6.

8. Jabbar A, Contractor Z, Ebrahim M, Mahmood K. Standard knowledge about their disease among patients with diabetes in Karachi, Pakistan. J Pak Med Assoc 2001; 51:216-8.

9. Mehrotra R, Bajaj S, Kumar D, Singh KJ. Influence of education and occupation on knowledge about diabetes control. Natl Med J India 2000; 13 :293-6.

10. Hawthorne K, Tomlinson S. Pakistani Muslims with type 2 diabetes mellitus: effect of sex, literacy skills, known diabetic complications and place of care on diabetic knowledge, reported self-monitoring management and glycaemic control. Diabet Med 1999; $16: 591-7$.

11. Hawthorne K. Effect of culturally appropriate health education on glycaemic control and knowledge of diabetes in British Pakistani women with type 2 diabetes mellitus. Health Educ Res 2001; 16 : 373-81.

12. Wee HL, Lisc HO. Public awareness of diabetes mellitus in Singapore. Singapore Med J 2002; 43:128-34.

13. Moodley LM. An assessment of the level of knowledge about diabetes mellitus among diabetic patients in a primary healthcare setting. SA Fam Pract $2007 ; 49: 54-9$

14. West JD, Goldberg KL. Diabetes self-care knowledge among outpatients at a veterans affairs medical center. American Journal of Health-system Pharmacy 2002; $59: 849$-52.

15. Nisar N, Khan IA, Qadri MH, Sher SA. Knowledge and Risk assessment of diabetes mellitus at primary care level: A Preventive approach required combating the disease in a developing country. Pak J Med Sci 2008; 24 :667-72.

16. Hassan ZU, Zia S, Maracy M. Baseline disease knowledge assessment in patients With Type II diabetes in a rural area of North West of Pakistan. JPMA 2004; $54:$ 67-73. 